\title{
Analisis Fikih Muamalah terhadap Tukar Menukar Nomor Undian Arisan
}

\author{
Yohan Sah*, Eva Fauziah \\ Prodi Hukum Ekonomi Syariah, Fakultas Syariah, Universitas Islam \\ Bandung, Indonesia.
}

*Yohansyah16@yahoo.com, eva.fauziah@unisba.ac.id

\begin{abstract}
Arisan with lottery number system is a type of arisan that uses the draw method to determine the winner of the arisan and agrees on the basis of the lottery that comes out by mutual agreement. However, the fulfillment of needs that must be met immediately makes some people try to get funding sources quickly, and of course in ways that are easier to go. The practice of exchanging arisan lottery numbers by PKK Kelurahan Cikawao Village is one way to be able to meet their needs. This study aims to determine the practice of exchanging arisan lottery numbers in Cikawao Village and to know the muamalah fiqh review of arisan lottery exchange numbers. This type of research is field research (field reseach) which is a type of research by collecting data at the place of the research problem. In this study using the method of observation, interviews, and literature study. After it is collected, processed and analyzed so that a conclusion can be drawn. From the results of research the practice of exchanging the social gathering numbers in terms of the contract is not justified based on the review of muamalah figh, because in the practice of exchanging, there is an agreement on overpayment at the time of the contract and this is called the practice of usury, so the practice of swapping lottery numbers This social gathering is forbidden / canceled.
\end{abstract}

Keywords: Arisan, qard, Buy and Sale

\begin{abstract}
Abstrak. Arisan dengan sistem nomor undian adalah suatu jenis arisan yang menggunakan metode pengundian untuk menetapkan pemenang arisan dan menyepakatinya berdasarkan undian yang keluar atas kesepakatan bersama. Akan tetapi, adanya pemenuhan kebutuhan yang harus segera dipenuhi membuat sebagian orang berusahan untuk mendapatkan sumber dana dengan cepat, dan tentu saja dengan cara yang lebih mudah untuk ditempuh. Praktik tukar menukar nomor undian arisan oleh ibu-ibu PKK Kelurahan Cikawao inilah yang menjadi salah satu cara untuk dapat memenuhi kebutuhannya. Penelitian ini bertujuan untuk mengetahui praktik tukar menukar nomor undian arisan di Kelurahan Cikawao dan untuk mengetahui tinjauan fikih muamalah terhadap tukar menukar nomor undian arisan. Jenis penelitian ini adalah penelitian lapangan (field reseach) yaitu jenis penelitian dengan cara mengumpulkan data di tempat terjadinya permasalahan penelitian. Dalam penelitian ini menggunakan metode observasi, wawancara, dan studi pustaka. Setelah itu dikumpulkan, diolah dan dianalisis sehingga dapat ditarik suatu kesimpulan. Dari hasil penelitian Praktik tukar-menukar nomor arisan tersebut dari segi akadnya tidak dibenarkan berdasarkan tinjauan fikih muamalah, karena dalam praktik tukar-menukar tersebut, terdapat kesepakatan kelebihan pembayaran pada saat akad dan hal ini dinamakan dengan praktik riba, sehingga praktik tukar-menukar nomor undian arisan ini hukumnya haram/batal.
\end{abstract}

Kata Kunci: Arisan, qard, jual beli 


\section{A. Pendahuluan}

Muamalah merupakan suatu kegiatan yang terjadi karena adanya interaksi antar sesama manusia. Hal ini dilakukan dengan adanya pemutaran harta, baik dengan cara tukar menukar barang atau sesuatu yang memberi manfaat dengan cara yang ditentukan, seperti jual beli, sewa menyewa, upah mengupah, dan sebagainya. Seiring perkembangan zaman, aktivitas muamalah di dalam masyarakat telah mengalami perkembangan yang sangat pesat. Fenomena sosial dalam bermuamalah yang dimaksud dapat ditandai bahwa aktivitas tersebut belum pernah ada pada masa Rasulullah saw.

Arisan merupakan suatu kegiatan yang dilakukan oleh beberapa orang dengan adanya penyerahan sejumlah harta dalam bentuk utang piutang yang dilakukan secara berkala. Maksudnya, arisan diberlakukan dengan masa atau waktu yang telah ditetapkan untuk memperoleh pemenang arisan pada periode tertentu. Salah satu bentuk arisan yang terjadi di Kecamatan Lengkong, Kelurahan Cikawao, Kota Bandung yaitu tukar menukar nomor arisan. Adapun pelaksanaan dari arisan ini pesertanya terdiri dari ibu-ibu PKK (Pemberdayaan Kesejahteraan Keluarga) yang melakukan pengundian arisan 2 minggu sekali. Objek yang diariskan itu uang beserta sembako dimana uang arisan itu disetor setiap 1 bulan sekali dengan nominal 300 ribu untuk jangka waktu 1 tahun. Hal yang menarik dari arisan tersebut dan yang menjadi catatan peneliti banyak sekali ibu-ibu PKK yang saling menukarkan nomor arisan baik karena kebutuhan yang mendesak atau karena iming-iming memperoleh uang lebih. Sebab apabila ada yang mau menukarkan nomor arisan terakhir dengan nomor arisan awal biaya tukaran nomor arisan sebesar 300 Ribu. Jadi biaya tersebut diwajibkan kepada penukar arisan dengan nomor terakhir dan diberikan kepada pemilik nomor arisan di awal. Jadi arisan ini bukan hanya sebatas menolong tapi ada unsur lain yang ingin didapat dari pemilik nomor terakhir.

Hal diatas berbanding terbalik dengan prinsip syariah. Dimana apabila terjadi kelebihan, hal tersebut tergolong ke dalam riba dan dapat merusak akad dikarenakan ada syarat yang tidak sejalan dengan prinsip syariah. Dengan melakukan pemberian keuntungan kepada pemberi pinjaman yang telah disyaratkan sebelumnya. Tujuan dari penelitian ini adalah Untuk mengetahui praktik tukar menukar nomor undian arisan di Kelurahan Cikawao Kecamatan Lengkong Kota Bandung, dan Untuk mengetahui tinjauan fikih muamalah terhadap tukar menukar nomor undian arisan di Kelurahan Cikawao,Kecamatan Lengkong Kota Bandung.

\section{B. Landasan Teori}

\section{Konsep Jual Beli}

Definisi jual beli secara bahasa yaitu memindahkan hak milik terhadap benda dengan akad saling mengganti. Landasan jual beli telah dijelaskan dalam al-qur'an dan hadist sebagai berikut

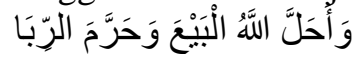

"Padahal Allah telah menghalalkan jual beli dan mengharamkan riba" (Q.S Al-Baqarah [2]: 275)

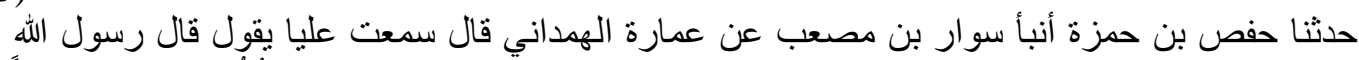

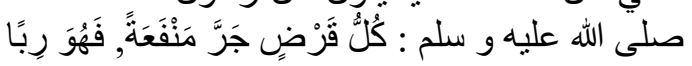

"Telah menceritakan kepada kami Abu Hurairah dari Rasulullah shallallahu 'alaihi wa sallam bersabda: "Bahwa Nabi Allah Daud 'alaihissallam tidak memakan makanan kecuali hasil usahanya sendiri.” (HR. Bukhari No. 1931)

Menurut jumhur ulama, rukun jual beli itu ada empat, yaitu: 1. Adanya orang yang berakad atau aqidain, yakni penjual dan pembeli; 2 . Adanya shighat (ijab dan kabul); 3. Adanya ma'qud 'alaih (objek/barang yang diperjualbelikan). Sedangkan syarat dalam jual beli adalah: 1. Saling rela antara kedua belah pihak; 2) Pihak-pihak yang melakukan akad telah dipandang mampu bertindak menurut hukum (mukallaf); 3) Harta yang menjadi objek transaksi telah dimiliki sebelumnya oleh kedua pihak; 4) Objek transaksi adalah barang yang dibolehkan agama; 5) Objek akad harus dapat diserahkan secepat mungkin setelah akad berlangsung; 6) Objek akad harus jelas dan dikenali oleh pihak aqid; 7) Harga yang disepakati kedua belah pihak harus jelas jumlahnya 
QARDH

Menurut Dr. Wahbah al-Zuhaili, qardh secara etimologis adalah sebagai berikut:

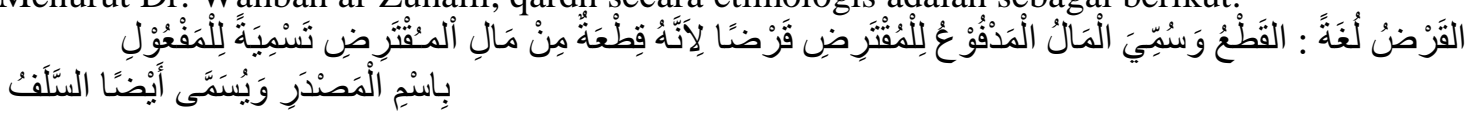

"Secara Bahasa, qardh artinya potongan, dikatakan demikian karena harta yang diserahkan kepada orang yang berutang secara potongan karena orang yang mengutangkan memotong dari sebagian harta yang dia miliki. Qardh merupakan bentuk isim mashdar, dikatakan juga dengan al-salaf"

Menurut Pasal 20 Kompilasi Hukum Ekonomi Syariah (KHES), qardh didefinisikan sebagai penyedian dana atau tagihan antara Lembaga keuangan Syariah dengan pihak peminjam untuk melakukan pembayaran secara tunai atau cicilan dalam jangka waktu tertentu. Adapun menurut Fatwa Dewan Syariah Nasional Majelis Ulama Indonesia (DSN-MUI) No. 19/DSNMUI/IV/2001 tentang qardh, yang dimaksud dengan qardh adalah pinjaman yang diberikan kepada nasabah (muqtaridh) yang memerlukan.

\section{Konsep Arisan}

Menurut Al-Khotslan menyebut arisan dengan istilah jam'iyyah muwaddhofin. Jam'iyyah sendiri bermakna perkumpulan atau asosiasi. Muwaddofin bermakna para karyawan. Jadi jam'iyyah muwaddhofin secara harfiah bermakna perkumpulan para karyawan. Hanya saja, makna perkumpulan karyawan di Arab telah memiliki makna istilah khusus yang sepadan dengan fakta arisan di Indonesia karena pelaku arisan di sana popular dan banyak dilakukan oleh para karyawan di berbagai unit kerja.

Mayoritas ulama berpendapat hukum arisan adalah mubah atau boleh. Ini adalah pendapat Ar-Rozi Asy-Syafi'I di kalangan ulama terdahulu, Abdul Aziz bin Baz, Muhammad bin Al-Utsaimin, Abdullah bin Abdurrahman bin Jibrin, dan fatwa Hai-ah Kibar Al-Ulama di Saudi Arabia Keputusan No. 164 tanggal 26/2/1410 H.

\section{Hasil Penelitian dan Pembahasan}

\section{Praktik Arisan di Kelurahan Cikawao Kecamatan Lengkong Kota Bandung}

Pelaksanaan dari arisan ini pesertanya terdiri dari ibu-ibu PKK (Pemberdayaan Kesejahteraan Keluarga) yang melakukan pengundian arisan 2 minggu sekali. Objek yang diariskan itu uang beserta sembako dimana uang arisan itu disetor setiap 1 bulan sekali dengan nominal 300 ribu untuk jangka waktu 1 tahun. Hal yang menarik dari arisan tersebut dan yang menjadi catatan peneliti banyak sekali ibu-ibu PKK yang saling menukarkan nomor arisan baik karena kebutuhan yang mendesak atau karena iming-iming memperoleh uang lebih. Sebab apabila ada yang mau menukarkan nomor arisan terakhir dengan nomor arisan awal biaya tukaran nomor arisan sebesar 300 Ribu. Jadi biaya tersebut diwajibkan kepada penukar arisan dengan nomor terakhir dan diberikan kepada pemilik nomor arisan di awal. Jadi arisan ini bukan hanya sebatas menolong tapi ada unsur lain yang ingin didapat dari pemilik nomor terakhir. Hal ini diasumsikan sebab di dalamnya terdapat kewajiban membayar sebesar 300 ribu kepada pemilik nomor awal.

Untuk dapat mempraktikkan sistem tukar menukar nomor urut arisan ini, terdapat beberapa hal yang lumrah dijadikan sebagai ketentuan, diantaranya yaitu: Pertama; Pembeli, yaitu pihak yang memiliki nomor urut arisan yang belakang dan ingin membeli nomor urut arisan yang depan. Kedua; Penjual, yaitu pihak yang memiliki nomor urut arisan yang depan atau awal dan menjual nomor urutnya kepada pihak yang ingin mendapatkan nomor urut awal. Ketiga; Saksi, yaitu pihak yang menyaksikan akad tukar menukar nomor urut arisan tersebut, dan biasanya dilakukan oleh ketua arisan. Untuk saksi ini tidak selamanya ada dalam transaksi, melainkan saksi bisa ada jika diperlukan saja. Maksudnya, apabila penjual dan pembeli merasa cukup dan saling percaya, juga dapat menjelaskan kepada anggota lainnya akan tindakan yang telah dilakukan mereka mengenai jual beli nomor urut, maka saksi dalam hal ini tidak diperlukan. Namun, ketua arisan tetap diinformasikan agar tidak terjadi kesalahpahaman. Kemudian apabila penjual dan pembeli dinilai tidak cakap dalam menginformasikan jual beli nomor arisan maka saksi sangat diperlukan. Hal ini agar transaksi jual beli nomor arisan itu 
tidak bardampak pada hal yang negatif bagi anggota lainnya seperti kecemburuan, kesalahpahaman, dan lain-lain.

Ketika seorang anggota arisan membutuhkan dana tunai cepat, sedangkan nomor urutnya berada pada urutan tengah atau akhir, maka dia (sebagai calon pihak 1) akan mencari anggota lain (sebagai calon pihak 2) yang memiliki nomor urut yang lebih awal darinya untuk ditukar. Pihak pertama disebut pembeli, sedangkan pihak kedua disebut penjual. Biasanya pembeli akan mendatangi rumah penjual, untuk membicarakan maksud dan tujuannya, kemudian setelah didapatkan kesepakatan, mereka pun akan menginformasikan kepada ketua arisan, supaya diketahui dan menghindari terjadinya perselisihan. Setelah itu, terjadilah transaksi tukar menukar nomor urut arisan antara pemenang undian arisan dengan calon pembeli nomor urut yang mengingikannya. Pada akad tersebut mereka bertransaksi dengan menetapkan besaran nominal uang yang harus dibayar oleh pembeli.

Tinjauan Fikih Muamalah Terhadap Tukar Menukar Nomor Undian Arisan Di Kelurahan Cikawao

Dalam tukar menukar no urut undian arisan, pihak yang berakad adalah: 1) Pembeli, yaitu pihak yang memiliki nomor urut arisan yang belakang dan ingin membeli nomor urut arisan yang depan. 2) Penjual, yaitu pihak yang memiliki nomor urut arisan yang depan atau awal dan menjual nomor urutnya kepada pihak yang ingin mendapatkan nomor urut awal. 3) Saksi, yaitu pihak yang menyaksikan akad jual beli nomor urut arisan tersebut, dan biasanya dilakukan oleh ketua arisan. Untuk saksi ini tidak selamanya ada dalam transaksi, melainkan saksi bisa ada jika diperlukan saja. Maksudnya, apabila penjual dan pembeli merasa cukup dan saling percaya, juga dapat menjelaskan kepada anggota lainnya akan tindakan yang telah dilakukan mereka mengenai jual beli nomor urut, maka saksi dalam hal ini tidak diperlukan. Namun, ketua arisan tetap diberitahu agar tidak terjadi kesalahpahaman. Kemudian apabila penjual dan pembeli dinilai tidak cakap dalam menginformasikan jual beli nomor arisan maka saksi di perlukan supaya transaksi jual beli nomor arisan itu tidak berdampak pada hal yang negatif bagi anggota lainnya seperti kecemburuan, kesalahpahaman, dan lain-lain.

Para pihak tersebut melakukan transaksi dengan sukarela dan tidak adanya paksaan satu sama lain. Kemudian mereka adalah orang-orang yang namanya sudah tercantum dalam buku catatan keanggotaan arisan, sehingga identitas dan latar belakang personal lainnya sudah dapat diketahui khususnya oleh masing-masing pihak yang bersangkutan, karena untuk menghindari kemungkinan terjadi perselisihan antar mereka, baik itu antar pembeli dan penjual maupun dengan anggota lainnya yang tidak terlibat, karena sudah diketahui oleh ketua arisan.

Dalam praktik utang-piutang nomor undian arisan yang dilakukan oleh masyarakat Kelurahan Cikawao, selalu mensyaratkan adanya manfaat yang akan diperoleh pemberi utang (muqridh). Wujud manfaat yang dimaksud yaitu dengan memberi uang tunai sejumlah yang ditentukan, yaitu 300.000 rupiah kepada pemberi utang selaku pemenang undian arisan. Maka dapat disimpulkan hat tersebut jelaslah haram karena ada unsur riba di dalamnya sebagaimana telah dijelaskan diatas.

Dilihat dari sisi lain, praktik utang-piutang merupakan suatu transaksi muamalah yang di dalamnya terdapat unsur tolong-menolong. Sebagai muqridh (orang yang memberikan utang), Islam menganjurkan kepada umatnya untuk memberikan bantuan kepada orang lain yang membutuhkan dengan cara memberi utang. Sedangkan dari sisi muqtaridh (orang yang berutang), utang bukan perbuatan yang dilarang, melainkan perbuatan yang dibolehkan karena seseorang berutang dengan tujuan untuk memanfaatkan barang atau uang yang diutanginya itu untuk memenuhi kebutuhan hidupnya, dan ia akan mengembalikannya persis seperti yang diterimanya.

Jadi, dapat penulis simpulkan berdasarkan data lapangan dan teori teori di atas, bahwa praktik tukar-menukar nomor undian arisan sebagaimana dipraktikan oleh kelompok arisan masyarakat kelurahan Cikawao, kecamatan Lengkong, kota Bandung lebih tepat dinamakan akad utang-piutang, bukan akad jual-beli. Kemudian, praktik utang-piutang nomor undian tersebut dihukumi haram, karena didalamnya terkandung riba qardhy, yaitu disyaratkan adanya kelebihan harta dalam pengembalian utang. 


\section{Kesimpulan}

Berdasarkan kajian yang telah penulis lakukan pada penelitian ini baik secara teoritis maupun analisis, akhirnya sampailah pada tahap kesimpulan. Pada bagian kesimpulan ini, ada beberapa hal yang menurut penulis anggap penting untuk dijadikan suatu konklusi dari pembahasan mengenai praktik tukar menukar nomor undian arisan di Kelurahan Cikawao Kecamatan Lengkong Kota Bandung, diantaranya yaitu:

1. Arisan dengan sistem nomor undian adalah suatu jenis arisan yang menggunakan metode pengundian untuk menetapkan pemenang. Akad yang digunakan dalam praktik tukarmenukar nomor undian arisan adalah akad utang-piutang, bukan jual beli. Hukum dasar arisan seharusnya menggunakan akad utang-piutang, dan bukan menggunakan akad jual beli.

2. Praktik pertukaran nomor undian arisan dengan penambahan uang Rp. 300.000 yang dilakukan oleh Ibu-Ibu PKK Kelurahan Cikawao Kecamatan Lengkong Kota Bandung, dalam tinjuan fikih muamalah adalah haram, karena di dalamnya terdapat kesepakatan adanya kelebihan uang pembayaran. Penambahan ini tergolong kepada bentuk transaksi riba ke dalam riba qardhy, yaitu disyaratkan adanya kelebihan harta dalam pengembalian utang, dimana pihak pengutang (muqtaridh) memberikan sejumlah uang kepada pihak pemberi utang (muqridh), dengan cara memotong uang tunai yang diterima muqtaridh dari muqridh.

\section{E. Saran}

Dari hasil penelitian ini penulis berharap dapat bermanfaat, khususnya bagi penulis pribadi, maupun bagi pihakpihak yang bersangkutan dan para pembaca. Kemudian berdasarkan penelaahan yang telah penulis lakukan secara mendalam, ada beberapa hal yang dapat penulis sampaikan sebagai suatu saran, yaitu:

1. Bagi Ibu-Ibu PKK Kelurahan Cikawao Kecamatan Lengkong Kota Bandung yang melakukan arisan dengan sistem nomor undian agar tidak melakukan praktik jual beli atau penambahan pembayaran atas pertukaran nomor undian arisan walaupun ada kesepakatan kelebihan pembayaran pada saat akad sebagaimana biasa dilakukan. Karena hal ini adalah perbuatan yang haram mengingat di dalamnya terkandung unsur riba yang dilarang dan tidak dibenarkan dalam syariat Islam.

2. Bagi pemerintah Kelurahan Cikawao Kecamatan Lengkong Kota Bandung, hendaknya dapat menyediakan dana talangan yang dikhususkan untuk warganya dengan syarat tidak ada kelebihan dana pengembalian yang diperjanjikan. Dana talangan itu bisa berasal dari dana swadaya masyarakat yang dikumpulkan secara periodik, untuk digunakan manakala terdapat warga yang membutuhkan. Dan ini bisa dilakukan dengan mudah dengan sistem yang mudah dan tentunya dengan pengawasan yang baik

\section{Daftar Pustaka}

[1]. Abu Abdullah Ahmad Ibn Muhammad Ibn Hanbal Ibn Hilal Ibn Asad al-Syaibani, (2001) Musnad al-Imam Ahmad Ibn Hanbal, (Tahqiq: Syu'aib al-Arnauth), Muasasah alRisalah, Beirut, Juz. XXVIII.

[2]. Adam, Panji. (2018). Fikih Muamalah Adabiyyah. Jakarta: Bandung: PT Refika Aditama.

[3]. Adam, Panji. (2018). Fikih Muamalah Maliyyah. Jakarta: Bandung: PT Refika Aditama.

[4]. Aziz, Abdul, M.A. (2010). Fiqh Muamalah; Sistem Transaksi dalam Islam. Jakarta: Amzah.

[5]. Az-Zuhaili,Wahbah. (2011). Fiqih Islam Wa Adillatuhu, Jakarta: Gema Insani.

[6]. Data Tahun 2019. Kelurahan Cikawao. Kecamatan lengkong. Kota Bandung.

[7]. Departemen Pendidikan Nasional. (2008). Kamus Besar Bahasa Indonesia. akarta: Pusat Bahasa.

[8]. Djuwaini dan Dimyauddin, (2008). Fiqh Mu'amalah, Jakarta: Pustaka Pelajar.

[9]. Djuwaini dan Dimyauddin. (2002). Pengantar Fiqh Muamalah. Yogyakarta: Pustaka Pelajar.

[10]. Dzajuli, A. (2007). Kaidah-Kaidah Fiqh,Kaidah Hukum Islam dalam Menyelesaikan Masalah yang Praktis. Jakarta: Kencana. 
[11]. Elly M, Setiadi (dkk). (2009). Ilmu Social dan Budaya Dasar. Jakarta: Kencana.

[12]. Fahmi, Widia (2017). Tinjauan Hukum Islam Terhadap Qard Dalam Praktik Arisan Uang Dengan Sistem Tawaran. Skripsi Fakultas Syariah Dan Hukum Universitas Islam Negeri Ar-Raniry Darusalam, Banda Aceh. 